\title{
Soft Skills for Sustainable Development in Tourism: The Bulgarian Experience
}

\author{
Teodora Kiryakova-Dineva ${ }^{1}$, Vyara Kyurova ${ }^{1}$ and Yana Chankova ${ }^{1}$
}

\begin{abstract}
The aim of this paper is to discuss the soft skills acquisition in the tourism industry as a means of education for sustainable development. A quantitative research approach has been applied in order to investigate the soft skills needed for tourism. The analysis is based on interviews carried out with representatives of the Bulgarian regional Chamber of Commerce and representatives of the Bulgarian hotel and restaurant industry. Additionally, a case study involving three groups of respondents, i.e. Learners, Educators and Representatives of business and Employers in the tourism and hospitality industry in Bulgaria was conducted based on a combined list of soft skills. Whereas some hard skills are traditionally taught at the educational institutions, soft skills, here identified as Core soft skills, Specific soft skills and Managerial soft skills, often remain beyond the educators' aims. Thus, the study provides some useful insights into the contemporary practice of tourism and hospitality education, on the one hand, and into the paradigm of education for sustainable development, on the other.
\end{abstract}

Keywords: Soft Skills, Tourism, Business, Hospitality, Education, Sustainability, Bulgaria

\section{Introduction}

In the global world of competitiveness among organizations, their ability to react quickly and flexibly to the new trends and the changing requirements and demands of the labor market has become an increasingly tangible advantage. Businesses are faced with the need to find and hire those workers who meet their production profile in the best possible way. In order for the companies to attain economic sustainability they need to develop a wide set of practices supporting long-term economic growth, the companies additionally have to create new products and technologies, to implement innovative and creative solutions and they also have to take account of the skills and competencies of their workers.

Along these lines, a number of funding programs of the European Commission, the Government of United Kingdom, 2018 and the ECEA programs, paired with other programs such as Australian Research Council, 2016 and US Department of Commerce, 2018, beyond the EU domain, especially support innovative education and skills training. Among the main goals is the introduction of new approaches to competences acquisition related to human capital, so that the competitiveness of the labour force can contribute directly to the firms' sustainability, the latter being a top priority in the modern business world. 
The authors support the view that the development of human capital is a key factor for sustainable development and hold that this as a successful way for balancing profitability in any kind of business activity. Moreover, due to the reduced budgets in the context of the economic crisis, the costs provided for human resources development are not always sufficient. Considering the paramount importance of the employees' qualifications for business success, companies are looking for new approaches to discovering, developing, stimulating, and retaining their highly qualified employees. This holds true for both the manufacturing industry and the sphere of services, including tourism.

In their study Tourism Education, Daniel, Costa, Pita, \& Costa (2017) raise the question: "What about entrepreneurial skills?" and ponder on the topic what skills should be trained in tourism education, allowing for the economic role of tourism that continues to count as one of the most important sectors on a world-wide scale (According to the UNWTO's long-term forecast report Tourism Towards 2030 will continue to grow annually and by 2030 its growth will amount to 1.8 billion, compared to the previous year (UNWTO, 2011).

This can be interpreted in several perspectives: firstly, in terms of the increased number of trips that will supposedly be international travels; secondly, in terms of the increased number of opportunities for new labor force to develop; and thirdly, in terms of the increased contacts between peoples and cultures. As a consequence, tourism education and training will develop along this new path and will rely on increasingly new parameters, and will go beyond traditional training standards and apply new forms of learning on a large scale (e.g. e-Learning, Blended Learning and other forms of knowledge transfer). In view of the development of new and alternative forms of tourism, it is also expected that new methods and courses will be introduced, taking into account the achievements of new technologies, and that these methods and courses will be developed in such a way as to meet the expectations of learners, as well as indirectly these of the employers. The relationship between trainers and employers needs to be taken into consideration, provided that many specialists point out to significant deficiencies in the direction of required and acquired level of tourism graduates' skills (e.g. Melo, 2017; Sisson \& Adams, 2013).

It is not only the transfer of knowledge and skills that often comes into focus (Hawkins, Elliott, \& Yu, 2012; Rao, Yang \& Yang, 2018) but also the need for bidirectional knowledge sharing is increasingly drawn attention to, whereby a critical need for intervention has been attested in order to create more effective relationships between the science of tourism and other sciences, such as new technologies, innovations, medicine and human health, ecology and natural resources, ethnology, religion, minorities and gender (Stoykova, 2018). In this vein, the people who will be hired in long-term tourism services will be qualified workforce and, respectively, they will need to have a broader range of professional skills and competences in order to meet the requirements of the global labour market.

A number of leading scholars and practitioners from the hospitality industry recognize some weak traits in tourism science:

- it is supposed to have a low uptake of research findings, arising from the fact that the tourism industry is spatially diffuse and at the same time highly fragmentary in terms 
ownership and structure, product and service offerings, as well as characterised by a highly changeable labour force (Bulgaria as indicated for the year 2014 and up to now; Shaw \& Williams, 2009);

- tourism science research comes under severe and persistent criticisms in relation to communication challenges (cf. Topler, 2017; Bitter, Kolupanova \& Zhidkova, 2015).

One such challenge derives from the nature of research being carried out, cf. Xiao and Smith (2007), specifically tourism research multidisciplinarity has both advantages and disadvantages, due to the fact that some of its disciplines make significant contributions to the conceptual framework and understanding, whereas others contribute more to instrumental, political and process uses; another communication challenge comes from language use, as it often happens that when academics and tourism entrepreneurs attempt to communicate and cooperate they seem to speak different languages - an academic one and a commercial one.

There is yet another language - the language used between clients and organizations and it is exactly this behaviour and language that necessitates the development of soft skills and this is the reason why we chose to focus our paper on the need for the development of a new set of soft skills and defined this set as a soft skills set for sustainable development in tourism.

\section{Problem Definition}

Except for being trained in specialized skills, hospitality industry staff also receives training in the skills of being ethical, flexible, tolerant, amiable and responsible, also known as soft skills. As a result of great misunderstanding, the soft skills required in hospitality settings have often been underestimated and even classified as low skills (Lundberg and Mossberg, 2008; Burns, 1997). On the contrary, other studies emphasize on the idea that soft skills should be paired with traditional technical skills to trace out the whole set of skills necessary for the tourism sector and crucially that soft skills are the most important set of skills sought after by tourism entrepreneurs (Christou et al., 2002). Soft skills prove to be of crucial importance for tourism, travel and hospitality employees in dealing with critical service situations and according to Watson and McCracken, 2002; Moser, 2018 this also holds true for management positions. Summing it up, it can be seen that the value of soft skills for tourism needs to be recognized and appropriate training methods for soft skills have to be developed.

Soft skills comprise, without being limited to, the following components: personal qualities, thinking skills, and interpersonal skills. The definitions of these components can be grouped according to the SCANS Skills and Competencies Report form 1991 elaborated by US Department of Labor, 1991, pp. 5-6). Within the group of personal qualities the following skills can be mentioned as being of greater importance: Responsibility, Self-esteem, Sociability, Self-management and Integrity/Honesty; Creative thinking, Decision making, Problem solving, Knowing how to learn and Reasoning and these are often conceived as skills related to the domain of thinking skills (Whetzel, 1992).

The authors of the present study believe that the development of soft skills for hospitality industry in Bulgaria should encompass and focus on the development of a 
greater set of skills to which more attention and transparency should be given. Setting this development as an objective in both formal and non-formal tourism and hospitality education is highly necessary.

\section{Methodology}

The applied methodology is based on a two-step analysis built upon two different questionnaires. The main reason for choosing a two-step method lies in its deductive ability for narrowing the wide set of soft skills for sustainable tourism development. Additionally, the need to include updated skills was a requirement for the subjects under study. The first step was aimed at limiting the scope of the most relevant soft skills needed for tourism. The authors contacted representatives of the Bulgarian regional Chamber of Commerce and representatives of the tourism and hospitality business in order to identify the soft skills, representatives of the hotel and restaurant industry were also interviewed, and finally a case study on the learners' and educators' opinions on the soft skills needed for the tourism industry in the territory of Bulgaria was conducted.

This broad scope was determined by the desire to probe the opinions of people with different profiles, employers as well as employees. The method of respondent selection is appropriate in terms of fieldwork with the interviewed people as it enabled direct contact with the respondents in the course of personal and group meetings. The survey was conducted between April and September 2018 and involved three groups of respondents: Learners, Educators and Representatives of business and Employers in the tourism and hospitality industry.

At the same time, the comprehensive survey of the issues under investigation was narrowed down to focus on the respondents' opinions regarding the role and importance of soft skills in professional development and qualification in the chosen spheres in Bulgaria in recent years.

In order to determine which types of soft skills could be helpful and beneficial in working for the given organizations, both in a specific and in a general way, e.g. organization of production processes, sales, staffing, customer services, efficient customer needs satisfaction, etc, a survey was conducted based on a list of soft skills prepared by the authors.

Respondents were asked to rate each skill and competency according to its relevance to effective performance in the relevant field of tourism industry. To be quite precise, they were asked to rate the importance of the skills and competencies on a 5 point Likert scale, ranging from critically important $(=5)$ to not very important $(=1)$. Questions on demographic data and information concerning their educational and employment status were also added.

Competencies were grouped into three sectors, namely core soft skills, specific soft skills and managerial soft skills. The respondents were provided with the opportunity to add additional skills to the list, if they consider these to be of importance.

In regard to the core skills for hospitality and tourism activity, the respondents have indicated the following soft skills competences: commitment, hospitality, customer focus, flexibility, effective communication, social skills, organization, action oriented and 
result-oriented competencies, responsibility and reliability, teamwork, sociability and communication adaptability, interpersonal communicative competence, social responsibility, self-control, environmental consciousness.

In the opinion of the interviewed participants the following soft skills were indicated as specific soft skills for hospitality and tourism activity: analytical thinking, safety, handling of complaints, customer focus, problem solving, guests safety, flexible interaction with colleagues, intercultural dialogue, adaptability, ability for digital interaction, organization and order, working under pressure, working with documents, self-development, social competencies, financial orientation.

Within the last group of soft skills - the group of the managerial soft skills, the respondents classified the following ones: decision making, employee motivation, leadership, team care, planning skills, delegation skills, strategic skills, time management, conflict management, process orientation, intercession skills (as pointed out by Thompson, 2009) and leadership.

In order to verify, if there is a statistically significant difference in the mean values of business leaders and employees in hospitality and tourism industry, on the one hand, and of learners and educators, on the other, the data distribution analysis is carried out by the means of classical one-way ANOVA test and by the non-parametric KruskalWallis test.

Given the objective of this research, the following six hypotheses have been formulated:

$\mathbf{H}_{1}$ - There is a statistically significant difference of the mean values among tourism business representatives/employers and learners concerning customer focus.

$\mathbf{H}_{2}$-There is a statistically significant difference of the mean values among tourism business representatives/employers and learners concerning handling of complaints.

$\mathbf{H}_{3}$ - There is a statistically significant difference of the mean values among tourism business representatives/employers and learners concerning the ability for digital interaction.

$\mathbf{H}_{4}$ - There is a statistically significant difference of the mean values among tourism business representatives/employers and educators concerning conflict management.

$\mathbf{H}_{5}$ - There is a statistically significant difference of the mean values among tourism business representatives/employers and learners concerning process orientation.

$\mathbf{H}_{6}$ - There is a statistically significant difference of the mean values among tourism business representatives/employers and educators concerning leadership.

\section{Empirical Study}

The empirical study was carried out on two stages. For the purposes of the analysis, the lists of competences proposed by Fournier and Inecon (2009), Redman and Wilkinson (2006) and Wilks and Hemsworth (2011) were combined with some of the abilities and skills listed under the Bulgarian National competence assessment network (www.en.mycompetence.bg). New soft skills were added to the compiled list, derived from the fist stage of the analysis and based on experience and deductive reasoning. The 
competences were subdivided into three categories: Core soft skills, Specific soft skills and Managerial soft skills.

For the purposes of the data collection stage, 125 respondents were contacted via e-mail and were asked to participate in a two-stage survey. They were asked to delineate the set of soft skills competences proposed by the authors by selecting the seven most important competences within three categories, i.e. core soft skills, special soft skills and managerial soft skills. The response rate at the first stage was $77 \%$, i.e. 96 learners, educators and representatives of hospitality business and employers. Based on their responses, a set of three main categories of soft skills was determined and prepared for accession during the second stage of the research.

The follow-up survey was conducted again via e-mail, whereby 96 questionnaires were distributed to the respondents of the first stage and sent back. In each group (learners, educators, business and employers) there were 32 actually completed questionnaires assessing the three sets of skills in view of their importance. The obtained variables were categorized according to their mean values as: 4.50 and above is estimated as "of critical importance"; those between 3.50 and 4.49 were assessed as "of considerable importance" and these below 3.49 - as "of moderate importance". Tables 1, 2 and 3 demonstrate the differentiation of competences according to their ranking. In this way the Tables show the soft skills of crucial importance assessed by the three groups of respondents, i.e. Learners, Educators and Business representatives and employers. The following analysis sheds light on the obvious differences between the values obtained for the three groups of respondents.

Additionally, the analysis determines the perspective of the future actions to be undertaken by the educators in order to secure effective relations between the group of the Learners and the group of the Business representatives and employers and to validate the chain of soft skills needed. The authors made use of deductive analysis approach in order to assess and evaluate the importance of the three categories of soft skills in terms of their achieved mean values.

\section{Results and Discussion}

The soft skills needed for tourism and hospitality industry subject to analysis and assessment within the three categories were evaluated as being of crucial importance, meaning that they were appropriately selected and that it is necessary for the three groups to work effectively together with respect to their acquisition and development. Taken separately, it can be claimed that within the category of Core soft skills the group of Learners identified the following skills: hospitality, teamwork and effective communication as being "of critical importance". The group of Educators assessed hospitality, customer focus and effective communication as "critically important" competences. Business representatives and employers rated four competences as "critically important", namely commitment, hospitality, customer focus and effective communication. Mean values and standard deviations for the Core soft skills are presented in Table 1: 
Table 1: Core soft skills needed for hospitality and tourism industry

\begin{tabular}{|l|c|c|c|c|c|c|}
\hline \multirow{2}{*}{ Core Soft Skills } & \multicolumn{2}{|c|}{ Learners } & \multicolumn{2}{c|}{ Educators } & \multicolumn{2}{c|}{ Business and employers } \\
\cline { 2 - 7 } & Mean & StD & Mean & StD & Mean & StD \\
\hline Commitment & 4.06 & .56 & 4.47 & .72 & 4,47 & .44 \\
\hline hospitality & 4.81 & .39 & 4.69 & .47 & 4.78 & .42 \\
\hline customer focus & 4.41 & .61 & 4.66 & .48 & 4.91 & .29 \\
\hline effective communication & 4.59 & .49 & 4.81 & .39 & 4.65 & .48 \\
\hline teamwork & 4.75 & .44 & 4.00 & .95 & 4.34 & .60 \\
\hline social responsibility & 3.28 & .68 & 4.16 & .37 & 3.94 & 0.35 \\
\hline environment consciousness & 3.41 & .66 & 3.81 & .59 & 3.97 & 0.59 \\
\hline
\end{tabular}

Source: own research

Table 1 demonstrates that the three groups of respondents evaluated the Core soft skills as skills of great importance and that only the group of the learners ranked two of them as skills "of moderate importance", namely the social responsibility and the environmental consciousness. In addition to the analysis of the first group of soft skills, hypothesis 1 was defined and verified. The verification of $\mathbf{H} \mathbf{1}$ by means of the classical statistical test ANOVA showed that the significance level F-Prob (Sig. ,000) is less than $\alpha$ $=0,05$. Consequently, we can assume that H1: "There is a statistically significant difference of the mean values among tourism business representatives/employers and learners concerning customer focus" has been verified. According to the non-parametric Kruskal-Wallis test, the significance level is Sig. $=0.000$ and thus less than $\alpha=0,05$. This means that $\mathbf{H} \mathbf{1}$ has been finally confirmed.

Within the range of special soft skills, the learners identified three soft skills as skills "of critical importance", namely professional behaviour, ability for digital interaction and handling of complaints, whereas the Educators indicated six soft skills: professional behaviour, handling of complaints, flexible interaction with colleagues, guests' safety, ability for digital interaction and intercultural dialogue. The latter group classified only one soft skill as being of less importance than the rest, and this is the ability to work under pressure. The representatives of the business and the employers evaluated all of the listed soft skills from the set of special competences as being of "critical importance", as shown in Table 2:

Table 2: Special soft skills needed for hospitality and tourism industry

\begin{tabular}{|l|c|c|c|c|c|c|}
\hline \multirow{2}{*}{$\begin{array}{l}\text { Special } \\
\text { Soft Skills }\end{array}$} & \multicolumn{2}{|c|}{ Learners } & \multicolumn{2}{|c|}{ Educators } & \multicolumn{3}{c|}{ Business and employers } \\
\cline { 2 - 7 } & Mean & StD & Mean & StD & Mean & StD \\
\hline guests' safety & 4.37 & .71 & 4.72 & .52 & 4.84 & .37 \\
\hline working under pressure & 4.47 & .67 & 4.44 & .50 & 4.53 & .51 \\
\hline professional behaviour & 4.81 & .39 & 4.88 & .34 & 4.81 & .39 \\
\hline handling of complaints & 4.66 & .54 & 4.81 & .39 & 4.91 & .29 \\
\hline flexible interaction with colleagues & 4.38 & .55 & 4.72 & .43 & 4.66 & .48 \\
\hline intercultural dialogue & 3.53 & .76 & 4.69 & .47 & 4.63 & .49 \\
\hline ability for digital interaction & 4.78 & .49 & 4.66 & .54 & 4.56 & .56 \\
\hline
\end{tabular}

Source: own research

Taking into consideration that special competences depend to a great extent on the teaching goals set by the educators and are especially required by the business and employers, the received mean values for all special soft skills competences are high as expected. 
The verification of $\mathbf{H} \mathbf{2}$ by the non-parametric Kruskal-Wallis test revealed that Sig. $=0.029$ and thus less than $\alpha=0,05$. As a result, we can suggest that the alternative hypothesis is valid and we can confirm this hypothesis' validity and accordingly assume that there is a statistically significant difference of the mean values among tourism business representatives/employers and learners concerning handling of complaints.

In an attempt to determine, if there is any statistically significant difference of the mean values among tourism business representatives/employers and learners concerning the soft skill ability for digital interaction $(\mathbf{H} \mathbf{3})$, an independent KruskalWallis test was performed. As a significance value of 0.067 is greater than the $\alpha$ level of 0.05, the null hypothesis has been accepted, i.e. the hypothesis claiming that both examined groups do not differ in terms of the way of perceiving the ability for digital interaction.

In view of the mean values, estimated for the managerial soft skills, an interesting fact can be observed: the managerial soft skills were assigned high mean values by the three groups. Their importance is revealed on the background of the more sustainable interpersonal relationships in the domain of the tourism and hospitality industry. They are also identified as being of paramount importance because of their relevance to the nature of the tourism product and in particular to its visibility at all stages - promotion, sales, realization of services. This fact necessitates the use of managerial abilities in order to assist tourism and hospitality companies to achieve their sustainable goals in regard to the quality of customer service and hospitality. The results of our survey show that the soft skills, needed for the management of the tourism product are estimated as skills of "crucial importance", as illustrated in Table 3:

Table 3: Managerial soft skills needed for hospitality and tourism industry

\begin{tabular}{|l|c|c|c|c|c|c|}
\hline \multirow{2}{*}{$\begin{array}{l}\text { Managerial } \\
\text { Soft Skills }\end{array}$} & \multicolumn{2}{|c|}{ Learners } & \multicolumn{2}{c|}{ Educators } & \multicolumn{2}{c|}{ Business and employers } \\
\cline { 2 - 7 } & Mean & StD & Mean & StD & Mean & StD \\
\hline decision making & 4.53 & .51 & 4.37 & .71 & 4.62 & .49 \\
\hline employee motivation & 4.81 & .39 & 4.44 & .50 & 4.78 & .42 \\
\hline team care & 4.47 & .51 & 4.28 & .73 & 4.84 & .37 \\
\hline conflict management & 4.62 & .55 & 4.47 & .72 & 4.91 & .29 \\
\hline time management & 4.69 & .47 & 4.28 & .77 & 4.84 & .37 \\
\hline process orientation & 3.59 & .66 & 4.16 & .37 & 4.75 & .44 \\
\hline leadership & 4.53 & .67 & 3.75 & .57 & 4.66 & .48 \\
\hline
\end{tabular}

Source: own research

Hypothesis 4 posits that: "There is a statistically significant difference in the mean values of Educators and Business/Employers as regards conflict management'. The examination of the Kruskal-Wallis test results revealed that the level of significance is 0.003 and is hence lower than $\alpha=0,05$. In view of this fact, we can say that $\mathbf{H} 4$ has been confirmed.

Hypothesis $\mathbf{5}$ states that there is a statistically significant difference in the mean values of Business/Employers and Learners with respect to process orientation. The significance value according to the test of Kruskal-Wallis is 0.000 and thus less than $\alpha=$ 0,05. This indicates that $\mathbf{H 5}$ has been verified.

Hypothesis 6 claims that there is a statistically significant difference in the mean values of the groups Business/Employers and Learners in regard to the managerial 
skill of leadership. The results of the ANOVA show that the significance level is 0.000 and hence less than $\alpha=0,05$. $\mathbf{H 6}$ has been therefore supported.

\section{Conclusion}

In the last decades, tourism has been influenced by the effects of global travelling and tourism services consumption, the profiling of tourism products and the differentiated behaviors towards socio-cultural and man-made environments. Since attitude-setting and consumer loyalty are not constant values, indeed they constantly change, the efforts of educators in travel and tourism have to be constantly aimed at providing the future tourism and travel specialists with the most relevant knowledge. Moreover, business leaders are not often willing to spend time on re-building the competences, acquired by the graduates. A huge gap between the expected and the actual workers' abilities emerges. In order for a tourism enterprise, hotel or travel agency to become economically sustainable, customer loyalty has to be a persistent goal. Consumer loyalty depends to a very great extent on tourism services' quality. To achieve this, intensive collaboration between all actors in tourism and hospitality has to be developed. In order to attain a sustainability impact, tourism education and the realization of tourism professionals have to go hand-in-hand since the competitiveness in tourism industry is strongly influenced by the relationship of tangible and intangible skill-sets. This fact has been taken into account by many educational institutions which constantly consider relevant feedback by tourism business leaders in order to improve their educational methods, but there is still certain lack in terms of acquiring the most updated skills the employers are looking for. This provided motivation for the present study which is aimed at finding out the most relevant soft skills for a sustainable tourism industry. During its first stage, the research evaluated and rated three groups of soft skills and identified them as core soft skills, special and managerial soft skills. The assessment of the three groups of skills was made by learners and educators, and business representatives and employers, respectively.

The achieved high mean values showed that all three selected groups of soft skills can be defined as skills of crucial importance. Based on the overall evaluation of skills by the learners it can be concluded that they rank the core soft skills as being of paramount importance, whereby hospitality, professional behavior and employee motivation are marked as the most important soft skills with respect to the three groups of skills. As especially important was considered the evaluation by representatives from the group of the tourism business leaders. For this reason, the second stage of the analysis used statistical data to prove, if there is significant difference in the assessment of soft skills differentiating in their mean values.

The confirmation of five of the six hypothesis by the results obtained showed that there are significant differences concerning the soft skills customer focus, handling of complaints, conflict management and process orientation and leadership, which were rated as more important than the other groups. The practical implication of these results illustrates that the acquisition of these skills needs to be included in tourism education and training. The identified soft skills need to be actively promoted amongst the groups of teachers and learners. 
It has to be emphasized that the estimated middle and high mean values of the assessed soft skills testify to their importance for the employment opportunities in the tourism and hospitality industry. The analyzed set of soft skills could not extend to cover all the skills relevant to the practice and theory of tourism, but it certainly provided useful information in view of the identification of the competencies and skills that should become inseparable part of the profiling of the successful young professionals.

Real efforts to provide up-to-date training and practice in order to acquire and utilize the mentioned set of soft skills in a more comprehensive way are to be expected. New skills and competences, not tackled in this paper, will have to be added as well, consequent upon the new trends in view of digitization, globalization, interculturality and multiculturalism, as they are indispensable part of professional and social life at present.

\section{References}

Annaraud, K. (2006). A Comparison of Skills Necessary for Successful Careers for American and Russian Hospitality Students Upon Graduation. Journal of Hospitality \& Tourism Education, 18(4), 33-44. doi:10.1080/10963758.2006.10696873

Becker, D. (2010). Zur Bedeutung von Soft Skills für Beschäftigte in der Hotellerie und Gastronomie. Scbulpädagogik Soft Skills, 150-161. doi:10.1007/978-3-86226-466-7_9

Bitter, N., Kolupanova, I., \& Zhidkova, I. (2015). Communicative competence and psychological aspects when interacting with client in tourism. Research Result. Pedagogics and Psychology of Education Series, 1(2).

Burns, P. M. (1997). Hard- skills, soft- skills: Undervaluing hospitality's 'service with a smile'. Progress in Tourism and Hospitality Research, 3(3), 239-248.

Christou, E. (2002). Revisiting Competencies for Hospitality Management: Contemporary Views of the Stakeholders. Journal of Hospitality \& Tourism Education, 14(1), 25-32.

Daniel, A. D., Costa, R. A., Pita, M. \& C. Costa. (2017). Tourism Education: What about entrepreneurial skills?, Journal of Hospitality and Tourism Management, 30, 65-72.

Gröschl, S. (2004). The Portfolio-An Alternative Assessment Method in Hospitality and Tourism Management Education. Journal of Hospitality \& Tourism Education, 16(1), 32-37.

Fournier, H., \& Ineson, E. (2009), Closing the Gap Between Education and Industry: Skills and Competencies for Food Service Internships in Switzerland Hospitality \& Industry Management, Paper presented at the International CHRIE-Conference, http://scholarworks.umass.edu/ sessions/wednesday/11

Hawkins, D. E., Elliott, S. M., \& Yu, L. (2012). Tourism Knowledge Sharing. Bridging Tourism Theory and Practice Knowledge Management in Tourism: Policy and Governance Applications, 33-53.

Hughes, K. (n.d.). Enhancing tourism graduates' soft skills: The importance of teaching reflective practice. Handbook of Teaching and Learning in Tourism, 95-106.

Lundberg, C., \& Mossberg, L. (2008). Learning by sharing: Waiters and bartenders experiences of service encounters. Journal of Foodservice, 19(1), 44-52.

Melo, A. (2017). Required And Acquired Level Of Graduates' Skills In Hospitality Management. doi:10.15405/epsbs.2017.01.02.21

Moser, M. (2018). Soft Skills als überfachliche Managementkompetenzen. Bedeutung Von Soft Skills in Einer Sich Wandelnden Unternehmenswelt, 3-16.

Rao, Y., Yang, M., \& Yang, Y. (2018). Knowledge Sharing, Organizational Learning and Service Innovation in Tourism. Journal of Service Science and Management, 11(05), 510-526.

Sisson, L. G., \& Adams, A. R. (2013). Essential Hospitality Management Competencies: The Importance of Soft Skills. Journal of Hospitality \& Tourism Education, 25(3), 131-145.

Sitompul, S. S., Kustono, D., Suhartadi, S., \& Setyaningsih, R. M. (2017). The Relationship of the Learning of Tourism Marketing, Hard Skills, Soft Skills and Working Quality of the Graduates of Tourism Academy in Medan. International Journal of Social Sciences \& Educational Studies, 3(4), 124-133. 
Stoykova, P. (2018). Feminization of the teaching profession in Bulgaria. Strategies for Policy in Science and Education, 6, 628-837.

Topler, J. P. (2017). Communication Skills in the Tourism Sector: The Speech Culture of Tour Guides. Tourism Culture \& Communication, 17(3), 217-223.

Tsankov, N., Gyuviyska, V. \& Levunlieva, M. (2018). Education for sustainable development. Strategies for Policy in Science and Education, 231-245.

Viens, N., \& Fortier, D. (2018). Sustainable Policymaking: Balancing Profitability \& Sustainable Development in Businesses. European Journal of Sustainable Development,7(4). doi:10.14207/ejsd.2018.v7n4p3

Watson, S., \& Mccracken, M. (2002). No attraction in strategic thinking: Perceptions on current and future skills needs for visitor attraction managers. International Journal of Tourism Research, 4(5), 367-378.

Whetzel, Deborah: The Secretary of Labor's Commission on Achieving Necessary Skills. ERIC Digest, available at: https://www.ericdigests.org/1992-5/skills.htm

Williams, A, M. \& Shaw, G. (2009), Future play: tourism, recreation and land use - a Foresight review. Land Use Policy, 12 9(1), 326-335.

Wilks, D. \& Hamswort. K. (2011). Soft skills as key competencies in hospitality higher education: matching demand and supply. Tourism and management studies, (7), 131-139. 
